\title{
MIGUEL DE UNAMUNO: SENTIMIENTO Y RAZON
}

Joaquim Clotet*

El mundo de las letras hispanas celebra el quincuagésimo aniversario de la muerte de don Miguel de Unamuno. El poeta, el filósofo y el literato se unieron en él creando una conciencia angustiada e irrepetible, paradójica y rebelde. Unicamente la muerte, por él siempre esperada y temida, adormeció en sueños de eternidad aquel corazón vehemente que supo estremecer a amigos y enemigos. El autoirreconciable Unamuno abrió el diálogo del silencio inaugurando la senda de la inmortalidad. Queda todavía en el horizonte la imagen del esposo y padre bondadoso, del profesor, del orador, del político, en una palabra, del hombre cuya voz era la autenticidad.

\section{$-1-$}

Intentaré, en primer lugar, con breves pinceladas, trazar la silueta espiritual de nuestro autor con el fin de conocer algunos rasgos que le caracterizan y distinguen. Voy a tropezar con una dificultad que a simple vista va a obstaculizar mi camino, pero no va a ser así dado que me va a proporcionar un primer dato esencial. Veamos al respecto un texto escrito por Unamuno en 1910: "Se ha dicho muchas veces que uno de los mejores modos de conocer a una persona es por los pasajes que subraya y señala en las obras que lee, y esta observación me ha guiado a no subrayar ni sệnalar pasaje alguno en mis libros para quitar al que los lea luego asideros por donde juzgarme. Pero aquí me encuentro con los pasajes que señaló en este libro de Balmes aquél que fui yo hace más de treinta años. Y es significativo para mí encontrar que mi antepasado - es decir, yo mismo a mis catorce o dieciséis años - señaló este pasaje del párrafo I del capítulo XXI de $E l$ Criterio, donde dice: 'La vida es breve, la muerte cierta; de aquí a pocos años el hombre que disfruta de la salud más robusta y lozana habrá descendido al sepulcro y sabrá, por experiencia, lo que hay de verdad en lo que dice la religión sobre los destinos de la otra vida'. 
¿Qué 'mio' era ese mi antepasado que señaló ingenuamente, en sus preocupa. ciones juveniles, este pasaje!"1 La resistencia al encasillamiento, a ser identificado, es una característica de su personalidad y un presupuesto epistemoló. gico de su filosofía. La confirmación o expresión de este aspecto se encuentra en la dialéctica que impulsa y acompaña su vida, la de sus personajes y su constitutiva bipolaridad temperamental: iracundo y sentimental, beato e irreverente, dogmático y perplejo, desafiante y pacato, místico y racionalista, republicano y anarquista. "Buscan poder encasillarme y meterme en uno de los cuadriculados en que colocan a los espíritus, diciendo de mí: 'Es luterano, es calvinista, es católico, es ateo, es racionalista, es místico', o cualquier otro de estos motes, cuyo sentido claro desconocen, pero que les dispensa de pensar más. Y yo no quiero dejarme encasillar, porque yo Miguel de Unamuno, como cualquier otro hombre que aspire a conciencia plena, soy especie única". ${ }^{2}$ Ahí está el cliché del hombre Unamuno con su grandeza y pequeñez, sinceridad y petulancia. Este aspecto singular unamuniano se reflejaba incluso en su propio porte según Julián Marías.

"¿Cuál ha sido la figura pública de don Miguel de Unamuno? En primer lugar, Unamuno provocaba una impresión de extrañeza; esta extrañeza se matizaba después postiva o negativamente, según el tono afectivo con que era vivida: don Miguel era 'admirable', 'original', 'genial', o bien, 'raro', 'extravagante', 'paradójico'. ¿Cuál era la razón de esta extrañeza, que importa retener?

La cosa empezaba por la figura corporal; don Miguel con su menuda cabeza de buho inquietante, inolvidable e inconfundible, su silueta esbelta y recia, su modo de vestir sencillo y un tanto inusitado, (...) ha sido durante muchos años un elemento pintoresco, azorante, curioso de la vida española". ${ }^{3}$

Otra de las causas de extrañeza era su cultura. Sus fuentes de formación no conocían los límites fronterizos. Estuvo particularmente interesado en las culturas anglosajona y germánica; de la francesa hay que destacar una figura para él importantísima Etienne Pivert de Sénancour autor de Obermann. Esta singularidad de Unamuno aumentaba porque en estas fechas la "intelectualidad" española, reunida principalmente en los círculos de la capital, permane-

1UNAMUNO, Un filósofo del sentido común, en Ensayos II, Madrid, Aguilar, 1942, p.1030.

${ }^{2}$ UNAMUNO, Mi religión, en op. cit., p.297.

${ }^{3}$ MARIAS, J., Filosofia española actual, Madrid, Espasa-Calpe, 5a ed., 1978. pp. 32-33. 
cía prácticamente cerrada a las corrientes e ideas provenientes de más allá de los Pirineos.

Su mundo interior, conocido principalmente por sus cartas, ofrecía la misma curiosidad a quienes de él han intentado aproximarse: "No quiero buscar mi paz interior en armonías, concordancias y compromisos que llevan a la estabilidad inerte, no quiero que firmen paz mi corazón y mi cabeza, ${ }^{4}$ sino que luchen entre sí, lealmente, pero con vigor. Soy y quiero seguir siendo un espíritu antinómico, dualista". 5 Este espíritu luchador, independiente, cuestionador de cuanto existe, hacen que Unamuno se centre en la pregunta fundamental del hombre - $i$ qué es vivir? - y en el sentido de la existencia humana. "la cuestión humana - escribe en su ensayo Soledad, en 1905 - es la cuestión de saber qué habrá de ser de mi conciencia, de la tuya, de la del otro y de la de todos, después de que cada uno de nosotros se muera," y en Del sentimiento trágico de la vida dice: "iPor qué quiero saber de donde vengo y a dónde voy, de dónde viene y a dónde va lo que me rodea y qué significa todo esto? Porque no quiero morirme del todo, y quiero saber si he de morirme o no definitivamente". 6

Este sentimiento, que como hemos visto le atormentaba ya desde joven, forma parte de su tejido existencial. Pero ¿es acaso Unamuno el único en pensar en la muerte y en lo que deba sucederla? Evidentemente que no. La originalidad de Unamuno consiste, sin pretender disminuir ni excusar su exacerbada sensibilidad ultratemporal, en que grita lo que otros también sienten pero callan, ocultan o disimulan.

¿Será posible, sin embargo, conocer los sentimientos íntimos y por ello mucho menos conocido de este hombre "agitador de espíritus"? ¿ Se dió en él la delicadeza del sentir y del afecto generoso? Acudamos al Epistolario de Unamuno y Joan Maragall, testimonio valioso de la amistad y consideración mutua que ambos autores se profesaron. Encontramos en el mismo aspectos que desvelan el corazón del Unamuno ignoto: "me restaura la mirada de mi mujer, que me trae brisas de mi infancia. Nos conocimos, de niños casi, em Bilbao; a los doce años volvió ella a su pueblo, Guernica, y allí iba yo siempre que podía a pasear con ella a la sombra del viejo roble, del árbol simbóiico. Y allí me casé. A mi mujer la alegría del corazón le rebasa por los ojos, y ante ella tengo vergüenza de estar triste. Un día hace años, cuando me preocupaba lo cardíaco, al verme llorar preso de congoja, lanzó uni hijo mío! que aún me repercute".?

${ }^{4}$ El subrayado es mío.

${ }^{5}$ UNAMUNO, Unamuno en sus cartas, en Ensayos II, ed. cit., p.XLVIII.

${ }^{6}$ UNAMUNO, Del sentimiento trágico de la vida. Madrid, Akal editor, 1983, p.87.

${ }^{7}$ UNAMUNO, Y MARAGALL, Epistolario. Barcelona, Catalonia, 2a ed., 1976, p.65. 
Con motivo del fallecimiento de su inestimable amigo escribe a Doña Clara Noble, Viuda de Joan Maragall: "Señora: Mi mujer me ha visto llorar al leer el telegrama en que mis amigos de La Publicidad me anuncian la muerte de su marido de usted y mi amigo, mejor aún mi hermano del alma". ${ }^{8}$ Que nadie se extrañe ante tales expresiones de afecto. Maragall había merecido conocer su alma desnuda: "me siento tan solo, amigo Maragall, tal solo... Si no fuese por mi mujer y mis hijos, por mi mundo que me lleva Dios". 9 "Todo esto me tiene triste y abatido". 10 "Estoy contristadísimo". ${ }^{11}$ "'Y iqué he de decirle yo que cada día me hundo más en mí mismo y me desintereso más, por tristeza y enojo, de lo que hago fuera?". ${ }^{12}$ Pero descubramos ahora parte del significado unamuniano de soledad, la soledad es el refugio de las almas robustas y soberbias, es la solución favorita en los dramas ibsenianos. ${ }^{13}$

Cual buen romántico, admirador de Wordsworth, Carlyle y de Goethe en quien según propia confesión habría aprendido el inglés y el alemán creía en el sentimiento y desconfiaba de la razón. "Estas gentes que vienen de la ciencia llegan a hacérseme insoportables; hay que decirles con Hamlet, aquello de 'hay muchas cosas que ignora tu filosofía'. Se atienen a la razón como única fuente de verdad y no oyen la voz del corazón". ${ }^{14}$ Afirma en otro lugar: "no sé si será verdad lo que alguien me dice y es que siento con la cabeza y pienso con el corazón". ${ }^{15}$ No es ajeno con estas afirmaciones al influjo del vitalismo y del historicismo para quienes razón y vida son términos antitéticos. La razón sólo conoce lo inmóvil, la vida es inestabilidad, fluencia, temporalidad. Ni tampoco podemos olvidar las ideas sobre el sentimiento de su coetáneo Max Scheler: "También lo emocional del espíritu, el sentir, preterir, amar, odiar, y querer tienen un contenido original y a priori, que no les ha sido prestado por el 'pensar' y que la ética ha de mostrar independientemente de la lógica. Hay un ordre du coeur o logique du coeur como atinadamente dice Blaise Pascal". ${ }^{16}$ Unamuno elimina al igual que Scheler el viejo prejuicio kantiano de que el espíritu humano se agota en el dilema "razónsensibilidad" o que todo lo que hay en el espíritu se ha de alinear bajo una u

${ }^{8}$ UNAMUNO Y MARAGALL, op. cit., p.115.

${ }^{9}$ UNAMUNO Y MARAGALL, op. cit., p.96.

10 UNAMUNO Y MARAGALL, op. cit., p.56.

11 UNAMUNO Y MARAGALL, op. cit., p.79.

12 UNAMUNO Y MARAGALL, op. cit., p.85.

${ }^{13}$ UNAMUNO, Ibsen y Kierkegaard, en Ensayos II, ed. cit., pp.346-347.

${ }^{14}$ UNAMUNO, Unamuno en sus cartas, en Ensayos II, ed. cit., p.XLVII.

${ }^{15}$ UNAMUNO Y MARAGALL, op. cit., p.12.

${ }^{16}$ SCHELER, M. Etica, I, Buenos Aires, Revista de Occidente, 1942, p.101. 
otra de estas categorías. De este modo se coloca también al lado de Shaftesbury y Hutcheson - contemporáneos de Joseph Butler, por él muy admirado y elogiado en Del sentimiento trágico de la vida - defensores de la teoría del sentido moral, cuyo desarrollo interesó notablemente al Kant precrítico.

\section{$-2-$}

La figura de don Miguel de Unamuno va unida, en el ejercicio de su actividad docente, al de la Universidad de Salamanca, la única que mereció su esfuerzo y dedicación total durante más de cuarenta años. Su nombre, cual nueva gema, sé engarza en la lista de personajes ilustres como Nebrija, el Brocense, Fray Luis de León, Francisco de Vitoria y otros que prestigiaron esta gran escuela del saber.

Según notas tomadas de su correspondencia, a Unamuno le agradó más en un primer momento Salamanca que la propia Universidad: "Salamanca no me disgusta; unos soberbios edificios rodeados de casuchas tísicas y callejas anémicas". ${ }^{17}$ "Nos vamos haciendo a este pueblo, que me gusta. Me intereso en sus menudencias y luchas de campanario, conozco a sus tipos, tipejos y calabazas; he empezado a hacerme sitio en él; encuentro buenos amigos y gentes con quienes hablar y todo va bien". ${ }^{18}$ Su primera reacción frente a la Universidad es bien diferente: "Según parece, a esta Universidad todo se le va en comisiones, misas, mascaradas y ceremonias". ${ }^{19}$ Su opinión va a mudar con el tiempo: "esta vieja ciudad de Salamanca sigue tan tranquila y sosegada como usted la conoció (...), pero por dentro, en su ambiente intelectual, en ganas de trabajar ha ganado mucho. La Universidad se ha fortalecido con elementos jóvenes y más entusiastas, se ha creado un Ateneo, menudean las conferencias y veladas, y esto va entrando en una vida mucho más intensa". ${ }^{20}$

Catedrático, Rector - dos veces - y miembro eminente de su Claustro siempre, son los hitos que jalonan su trayectoria en la sede del saber de la ciudad del Tormes. Enemigo de la algarabía de las grandes urbes, amaba el recogimiento y la quietud castellanas sin que por ello se considerase alejado de los intereses universales de la cultura, aduciendo a tal efecto el ejemplo de Kant sabia y conscientemente recluido en la prusiana Königsberg.

Por Real Orden de 7 de julio de 1891 es nombrado Catedrático de Lengua Griega de la Universidad de Salamanca tras haber ganado las oposiciones

\footnotetext{
${ }^{17}$ Unamuno a Múgica, en Cartas inéditas de Unamuno, recopiladas por Sergio Fernández Larrain, Edit., Rodas, 1972, 2a ed., p.70.

${ }^{18}$ Unamuno a Múgica, en op. cit., p.141.

${ }^{19}$ Unamuno a Múgica, en op. cit., p.139.

${ }^{20}$ Unamuno a Matilde B. de Ros, en Cartas inéditas de Unamuno, ed. cit., p.357.
} 
correspondientes ante un tribunal presidido por don Marcelino Menéndez y Pelayo. Su espíritu luchador se había puesto de manifiesto con anterioridad en otras cuatro pruebas de oposición, dos de filosofía y otras dos de lengua latina, que no le fueron favorables, así como el concurso a una cátedra de vascuence convocada por la Diputación de Vizcaya (1888). La independencia intelectual y su carácter polémico fueron sin duda una de las causas que impidieron el acierto en los ya de por sí ingratos ejercicios de oposición.

Por Real Decreto de 26 de octubre de 1900 es nombrado Rector. Veamos el comentario del propio Unamuno en una carta de 19 de octubre de 1900: "La cosa se ha sabido aquí, habiendo caído como una bomba. Figure usted eso de nombrar un Gobierno conservador a un socialista, heterodoxo, propagador de ideas disolventes, que no pasa de treinta y seis años, que no es de la ciudad, que sólo lleva nueve años en el profesorado". ${ }^{21}$ El nuevo cargo no disminuyó su tarea docente, además de ocupar su cátedra llamada con posterioridad de Lengua y Literatura Griega, pasa a ocupar desde noviembre de 1900 la de Filología Comparada del Latín y el Castellano, que más tarde se denominaría de Historia de la Lengua Castellana.

El 20 de agosto de 1914 se depuesto del cargo inesperadamente. La falta de explicaciones por este hecho le causó un gran malestar. Ortega y Gasset, lamentando el acontecimiento, se quejaba en un periódico de Madrid: "Personalmente no me unen al Sr. Unamuno más que polémicas agrias y a veces violentas. Se trata de que España tiene muy pocos 'hombres adecuados en el lugar adecuado'. Y no haberá ningún patriota dispuesto a que por un necio capricho, ignoro de quien, le falte uno más". ${ }^{22}$ Destituido del rectorado, Unamuno se limitó, con la exigencia y puntualidad de siempre, a sus dos aulas cotidianas de Lengua y Literatura Griegas y de Historia de la Lengua Castellana. En 1921, a petición del Claustro, es designado Vicerrector, y en el mismo año a petición de la Junta de Professores de la Facultad de Filosofía y Letras es propuesto para Decano. La actitud de oposición al golpe de Estado del General Primo de Rivera hace que sea confinado por éste a la isla de Fuerteventura, donde pasará cuatro meses. De allí fue a París y luego a Hendaya con el fin de auscultar los latidos de la ausente pero próxima España. La sed de eternidad, dolencia hiriente que nunca le abandonó, hizo que en el destierro suspirara con el poema que comienza así:

\section{"Si caigo aquí, sobre esta tierra verde \\ mollar y tibia de la dulce Francia,}

${ }^{21}$ GARCIA BLANCO, M., Don Miguel y la Universidad, en Cuadernos de la Cátedra Mi. gual de Unamuno, XIII, Salamanca, Facultad de Filosofia y Letras, 1963, p.19.

${ }^{22}$ ORTEGA Y GASSET, J., La destitución de Unamuno, en El País, Madrid, 17 de octubre de 1914. 
si caigo aquí donde el hastío muerde celado en rosas de sutil fragancia, si caigo aquí, oficina del buen gusto donde sólo el olvido da consuelo, llevad mi cuerpo al maternal y adusto páramo que se hermana con el cielo". ${ }^{23}$

Seis años duró su exilio. Vuelve en 1930 a su Salamanca querida y a sus aulas entrañables. Adviene la República en 1931, a propuesta del Claustro es nombrado nuevamente Rector y elegido como Diputado a Cortes.

En la inauguración académica del Curso 1931-1932, día en que se cumplía el quadragésimo aniversario de su llegada a la misma Universidad, abrió nuevamente el ejercicio de las actividades universitarias - como también lo hiciera en 1901, en el inicio de su primer rectorado - "y lo abrí - entonces - como se hacía, en nombre de su Majestad el Rey". "Vine como Rector nombrado por Real Decreto de doña María Criştina de Habsburgo, Reina Regente de España. Y aquí debo hacer una declaración de fe monárquica. Y estuve abriendo cursos trece años consecutivos, excepto el de 1904, hace veintisiete, en que vino a abrirlo el entonces Rey, don Alfonso XII...". "Corre el tiempo y llega este acto de 1931-1932, y vuelvo nombrado Rector por mis compañeros y bajo un nuevo régimen". - La expectación de los oyentes va en aumento. Algo inaudito y de contenida vehemencia parece que va a surgir de la boca del ilustre orador -. "En nombre de Su Majestad España, una, soberana y universal, declaro abierto el curso de 1931 a 1932 en esta Universidad universal y española de Salamanca, y que Dios Nuestro Señor nos ilumine a todos para que, con su gracia, podamos en la República servirle sirviendo a nuestra común madre Patria". ${ }^{24}$ Un ejemplo más del arrojo y singularidad del carácter unamuniano. Ni con la monarquía ni con la república. Solo. Inclassificable Unamuno.

En 1934 - año de su jubilación - se le nombra Rector vitalicio de la Universidad y se crea la Cátedra que lleva su nombre, y su Facultad, en 1935, propone su candidatura para el Premio Nobel de Literatura y que, como tantos hispanoparlantes de auténtico valer, nunca obtuvo. Fue nombrado también "Doctor honoris causa" por la Universidad de Oxford y la de Grenoble.

Considero importante analizar brevemente el interés de Unamuno por la renovación y mejora de la Universidad, en primer lugar la suya, y luego la enseñanza y la cultura en general en el país. El ejercicio de sus funciones se le presenta como un medio para europeizar y salvar a España, inquietud por

\footnotetext{
${ }^{23}$ GARCIA BLANCO, M., op. cit., p. 26 .

${ }^{24}$ GARCIA BLANCO, M., op. cit., p. 28.
} 
otra parte común con otros intelectuales de la época. Este interés es particularmente manifiesto en el período de su primer rectorado. Desencantado de sus relaciones con el Partido Socialista Obrero y con Pablo Iglesias, Unamuno se reafirma en su actitud espiritualista-idealista y de fe en sí mismo, estimulado por la correspondencia que mantiene con don Francisco Giner de los Ríos.

Es sabido que Unamuno en La Enseñanza Superior ${ }^{25}$ había planteado el papel de la Universidad en la renovación espiritual de España con una dura crítica a esta institución. Ahora bien, es en su discurso inaugural del curso académico 1900-1901, de tono parenético y desiderativo, donde se hace explícita su vocación educadora y social:

"Toda vuestra actividad académica fuera de esta Casa redúcese, a lo que sé, a reuniros en otra parte para discursear y discutir sobre lo que otros formularon o pensaron. No os reunís para fines genuinamente científicos, de ciencia que se hace y no de la que se recibe hecha, pero os falta tiempo así que se os ofrezca el más liviano pretexto para echaros de holgorio por esas calles paseando las banderas de las Facultades. (...) Ojalá viniéseis todos henchidos de frescura sin la huella que os han dejado quince o veinte años de exámenes y trayendo a estos claustros no ansias de notas, sino sed de verdad y anhelo de saber para la vida". ${ }^{26}$

El programa del nuevo Rector se nos revela en alguno de los fragmentos de una carta de 13 de noviembre de 1900 a don Francisco Giner de los Ríos. En ella expresa su convicción de que la tarea universitaria verdadera debe repercutir en la mejora de la realidad social, es decir, intelectual y espiritual como un todo. "Pienso, sobre todo, dirigirme a los estudiantes, reunirlos, acudir a sus asociaciones, excitarlos a estudiar en vivo costumbres, tradiciones, lenguaje, estado social, situación obrera, etc... (...) Dentro de unos días voy a ésa a ver al Ministro y si puedo hacer en esta Escuela la revolución desde arriba, enconces procuraré verle. (...) !Trabajar, trabajar, trabajar, trabajar! ¿Que me desparramo?!Bah! Así será mi obra menos lúcida para mí, tal vez no menos honda. (...) No quiero negarme a nada, no quiero ser un ambicioso; prefiero ser un pródigo espiritual, un agitador. (...) Lo he dicho y lo repito: siembro sin mirar atrás, lo demás es de Dios. ¿No es acaso mejor haber fomentado la vida espiritual íntima de los que nos rodean a no dejar un nombre,

\footnotetext{
${ }^{25}$ Artículos publicados por Unamuno en la revista Vida Nueva, a principios de 1899. ${ }^{26}$ UNAMUNO, Discurso en la apertura del curso académico de 1900-1901 en la Universidad de Salamanca, en Obras Completas, VII Madrid, pp.493-504.
} 
Miguel de Unamuno: Sentimiento y Razón

una flatus vocis, encadenado a un libro? Me desparramaré, sin cálculos egoístas. Así lo hace usted y por eso le queremos tanto". ${ }^{27}$ Imposible dejar de admirar el valor de estas líneas por la actitud ética en ellas manifiesta: sentido de responsabilidad, afán por el trabajo, entrega total a las exigencias del nuevo cargo, espíritu de superación y crecimiento personal y colectivo.

El 25 de noviembre de 1914, ya destituido del cargo, don Miguel lee una conferencia en el Ateneo de Madrid titulada Lo que ha de ser un Rector en España, de entre sus apasionadas palabras conviene retener éstas: "He procurado cumplir mi missión, mi destino, de hacerme hombre universitario de la España universal". ${ }^{28}$

Unamuno había dicho que quería "escribir filosofía en la lengua en que se pide el chocolate y se habla de la cosecha y de los asuntos domésticos". ${ }^{29}$ Su intención no va a concretarse en la producción de una nueva teoría especulativa, metodológica, científica o hermenéutica. La filosofía, su filosofía, surge de la propia vivencia, de su propia problemática, de las cuestiones que le intranquilizan y desesperan, de su incómoda existencia. Esta sería su filosofía de puertas a dentro, para sí, aunque manifiesta a los otros en sus escritos y discursos. De puertas a fuera, aspecto relacional y social, la filosofía tiene en Unamuno, entre otros aspectos, un carácter socrático. Pretenderá hacer descubrir por sí mismos, a los demás, la propia ignorancia e inconsciencia; cuando esto no sea efectivo llegará a azuzarles con el insulto o el desafío. Es preciso que las personas en España, individual y colectivamente, despierten de su "ñoñez", "ramplonería", "africanismo", "mandarinismo", o de su estado "tibetano" con el fin de que abandonen su condición primitivista, de ignorancia, o inconsciencia y lleguen a ser ellas mismas, es decir, que tomen como metas: educarse, instruirse, valorarse, "europeizarse". Este último término manifiesta su concepción histórica de la vida y su visión evolucionista y perfectible del hombre y de la sociedad que había aprendido en Spencer.

España y la mayoría de los españoles de su época no habían alcanzado aún el grado de desarrollo espiritual y cualitativo que les correspondía según la evolución histórico-cultural por la que se movían las más importantes naciones europeas. Era necesario motivarles, invitarles al cambio, de ahí, el carácter socrático de su filosofía al que acabo de referirme. Quisiera ahora matizar mi afirmación. Sócrates se considera, según la versión de Platón, en la Apologia de Sócrates, una especie de tábano que ha de aguijonear un caballo grande y de buena raza pero tardo y remolón, que simboliza la ciudad de Ate-

${ }^{27}$ UNAMUNO, Carta a Giner de los Ríos, /en GOMEZ MOLLEDA, D., Unamuno "agitador de espiritus" $y$ Giner. Correspondencia inédita, Madrid, Narcea, 1977, pp.62-63.

${ }^{28}$ UNAMUNO, Obras completas, ed. cit., VII, pp.877-878.

${ }^{29}$ UNAMUNO Y MARAGALL, Epistolario, ed. cit., pp.20-21. 
nas. El encargo le ha sido confiado por el dios de la ciudad. ${ }^{30}$ Existe en Unamuno, lo confirma la Profesora Dolores Gómez Molleda, un "sentido de misión", un "autoconvencimiento" respecto a su "labor personal de agitador de espíritus", "sembrador de inquietudes", de "disconformidades", de "ideas agudas", de "interrogantes", "una fe en la que el cambio de ciertos valores es trascendental para España". ${ }^{31}$

Acudamos al propio don Miguel que en una carta de 1903 afirma confidencialmente: "Desde hace algún tiempo, desde que pasé cierta honda crisis de conciencia, se va afirmando en mí una profundísima persuasión de que soy instrumento en manos de Dios para contribuir a la renovación espiritual de España". ${ }^{32}$

Esta tarea redentora se circunscribe genéricamente, en el sentir y hacer unamunianos, al campo de la cultura. Con esta óptica nos será más fácil entender el "quijotismo agresivo", la provocación, el apóstrofe, que proliferan en su vida y escritos al dirigirse a los estudiantes en sus discursos, al pueblo llano y a los gobernantes en sus artículos de prensa, a los pseudointelectuales y nacionalistas en sus conferencias por la amplia geografía española.

La producción unamuniana tiene, independientemente de los géneros y formas adoptados, otras características comunes, que la generan y desarrollan.

La fuerza o "vis" impulsiva de su obra procede de la incapacidad de la razón para dar respuesta a la pregunta fundamental sobre la vida individual y concreta (irracionalismo vitalista), y de la asunción de una conciencia histórica, como aspecto constitutivo dinámico de la existencia humana (protagonismo histórico humano).

El centro de la filosofía de don Miguel de Unamuno es el hombre, el "hombre concreto", el "hombre de carne y hueso", como él acostumbraba a escribir, y dentro del hombre, la vida.

Esta vida se caracteriza por el ansia de no morir o por el deseo de inmortalidad. La imposibilidad de la razón en dar una respuesta o una solución al enigma d€ la vida (aniquilación-perduración), lleva como consecuencia a la concepción y vivencia de la vida como angustia o "congoja". Angustia o "congoja" de la que Unamuno es el modelo viviente; miedo, pena y soledad acompañan el transcurrir de su vida íntima. Siente el impulso y el deseo de vivir para siempre y no da con una explicación concluyente y clara - racional - que le resuelva su inquietante incógnita. Se trata de una lucha entre

${ }^{30}$ PLATON. Apologia de Sócrates, traducció de Joan Crexells, edició a cura de Josep Vives, Barcelona, Editorial Laia, 1981, 30e-31a.

31 GOMEZ MOLLEDA, D., Unamuno "agitador de espiritus" $y$ Giner..., ed. cit., p.65.

32 Unamuno a Múgica, en GOMEZ MOLLEDA, D., op. cit., p.52. 
Miguel de Unamuno: Sentimiento y Razón

pensar y sentir, razón y deseo, cabeza y corazón. "¿Contradicción? iYa lo creo! iLa de mi corazón, que dice sí, y mi cabeza, que dice no!”33

Es una dramatización del dualismo kantiano del conocimiento, autor a quien conocía muy bien, del mismo modo que a Spinoza y Hegel. La falta de conciliación entre las ideas de la razón conduce a Kant hacia la negación de la metafísica como ciencia, el mismo problema lleva a Unamuno a la tragedia de la conciencia consigo misma, a la trage dia constitutiva de la propia existencia. La posible solución de la aporía existencial (razón-sentimiento) por medio de la creencia religiosa le resulta inalcanzable puesto que la fe, en sí misma, se le ofrece como problemática. Las denominadas "pruebas racionales" de la existencia de Dios, siguiendo a Kant, ya no prueban nada. Unamuno está "acongojado" desde la incerteza e inestabilidad de su fe. Kierkegaard, el gran atormentado de la primera mitad del siglo XIX, para otros el "Sócrates cristiano del XIX", está angustiado a través y a pesar de su fe inquebrantable. La angustia kierkegaardiana tiene una dimensión fundamental ético-religiosa: la justificación ante el Absoluto Trascendente. La "congoja" de Unamuno procede de su misma constitución de ser viviente-sentiente que se interroga por su continuidad o persistencia como tal, al margen de sentimientos de indignidad, responsabilidad o temor frente a Dios.

Para terminar, y con relación a la querida lengua y literatura portuguesa, no puedo dejar de leer parte del contenido de una carta de Unamuno a su amigo estadounidense Benjamin Burges Moore, en viaje por tierras de Portugal, y que quiere adentrarse en el conocimiento de la literature portuguesa: "Hace tiempo que estaba pensando escribirle, amigo mío, cuando me llega su carta. Me alegro que se haya usted aficionado a las cosas portuguesas. Portugal, este país trágico-idílico, merece ser conocido. Si ha leído usted Camões, Garrett y algo de Eça de Queiroz (de éste lo mejor es $A$ reliquia y $A$ cidade e as serras y Correspondência de Fradique Mendes), le recomiendo que lea las obras de Oliveira Martins. Su História de Portugal, dos pequeños volúmenes, y los otros dos del Portugal contemporâneo. En esta última obra hay cosas admirables. No conozco historiador moderno que me sugiera más y lea su libro Os filhos de Dom João I. Un poeta en que hallará cosas tiernísimas y una sencillez de expresión insuperable es João de Deus. Toda su obra poética se encierra en un tomito: Campo de flores. De Camilo Castelo Branco le recomiendo, al menos tres novelas: Amor de perdição, $A$ queda d'um anjo y $A$ mulher fatal. Pobre de ideas, pero riquísimo de emoción y de fondo trágico. No deje tampoco Pátria y Os simples, de Guerra Junqueiro, y Constança, de Eugenio de Castro. Hay una buena historia de la Literatura portuguesa - la de Mendes dos Remédios -, con una variada antología. Es una guía excelen-

${ }^{33}$ UNAMUNO, Del sentimiento trágico de la vida, ed. cit., p.69. 
te". ${ }^{34}$ Es ésta una característica más de este vasco ilustre, con renombre internacional. Es preciso reconocer que por la calidad de su obra, por su esfuerzo en la renovación intelectual de España, por su actitud política ante la dictadura de Primo de Rivera y durante la República, merece un lugar destacado en la galería de los personajes incómodos pero valiosos de la España del siglo XX.

${ }^{34}$ PREDMORE, R.L., Tres cartas inéditas de Unamuno, en Cuadernos de la Cátedra Miguel de Unamuno, XIV-XV, Salamanca, Facultad de Filosofia y Letras, Universidad de Salamanca, 1964-1965, p.66.

*Departamento de Filosofia.

Pontifícia Universidade Católica do Rio Grande do Sul

90.620 Porto Alegre-RS 